\title{
Primary extragenital endometrial stromal sarcoma of the lung: first reported case and review of literature
}

\author{
Lara Alessandrini ${ }^{1 *}$, Francesco Sopracordevole ${ }^{2}$, Giulio Bertola ${ }^{3}$, Simona Scalone ${ }^{4}$, Martina Urbani ${ }^{5}$, \\ Gianmaria Miolo ${ }^{4}$, Tiziana Perin ${ }^{1}$, Fabrizio Italia ${ }^{6}$ and Vincenzo Canzonieri ${ }^{1}$
}

\begin{abstract}
Background: Endometrial stromal sarcomas arising in extrauterine and extraovarian sites, in the absence of a primary uterine lesion are quite rare, especially in the absence of endometriosis. They usually present as an abdominal or pelvic mass lesion.

Case presentation: In 2007, a 45-year-old woman underwent total hysterectomy for in situ squamous cell carcinoma of the cervix. In 2014, an upper left pulmonary lobectomy was performed for a mass, which was provisionally diagnosed as primary carcinosarcoma of the lung. A second histological revision of the lung surgical specimen was performed in the Pathology Unit of our Institute. After extensive immunohistochemical analyses, the preferred diagnosis was spindle-cell sarcoma, consistent with high-grade extragenital endometrial stromal sarcoma (EESS). A review of all slides of the hysterectomy specimen confirms the original diagnosis: no evidence of stromal tumor was found. Afterwards, the patient developed multiple and metachronous pulmonary lesions and a scapular soft tissue mass, which showed the same morphophenotypic features of the first lung mass. The patient was treated with antiblastic therapy, surgical resection and radioablation, when appropriate. To date, the patient has no signs or symptoms.

Conclusions: The authors present the first case of primary EESS arising in the lung with no association with endometriosis published to date. Detailed clinical history and follow-up are also described. Moreover, extensive literature review is reported, along with differential diagnoses, immunohistochemical and molecular findings, pathogenetic hypotheses and treatment options. The knowledge of EESS potential extrauterine location and of its peculiar morphophenotypic aspects are required for a correct diagnosis, and for choosing the most suitable treatment.
\end{abstract}

Keywords: Extragenital endometrial stromal sarcoma, Lung, Immunohistochemistry, Case report

\section{Background}

Endometrial stromal sarcoma (ESS) is an uncommon mesenchymal tumor of the uterus, which accounts for less than $1 \%$ of all uterine malignancies but it is the second most common uterine malignant mesenchymal tumor [1]. The latest World Health Organization Classification [1], categorizes ESS into low-grade ESS (LGESS), high-grade ESS (HGESS) and undifferentiated endometrial sarcoma (UES). LGESS are typically composed of cytologically bland fusiform cells resembling stromal cells of proliferative-phase endometrium, intermingled

\footnotetext{
* Correspondence: lara.alessandrini@cro.it

${ }^{1}$ Pathology, IRCCS-National Cancer Institute, Via F. Gallini 2, 33081 Aviano, Italy Full list of author information is available at the end of the article
}

with numerous small plexiform arterioles, permeating the myometrium as well as the intramyometrial or parametrial vessels. The mitotic rate is usually lower than 5 mitoses/10HPF. They show an indolent course: recurrences and metastases are rare and occur after long periods of time $[1,2]$. In contrast, both HGESS and UES have a malignant behavior. They often exhibits myometrial invasion, hemorrhage and necrosis, as well as marked nuclear pleomorphism with round cell morphology (and a minor component part of low-grade spindle cell morphology) and high mitotic activity with 10 mitoses/10HPF or higher. Patients are more likely to develop recurrences and die from disease. The most important morphologic feature that distinguishes ESS from 
UES is that the latter lacks overt resemblance to proliferative endometrial stroma.

Endometrial stromal sarcomas arising as primary tumors in extrauterine and extraovarian (i.e., extragenital endometrial stromal sarcomas) sites are quite rare, and reported in the English medical literature as small series or case reports (Table 1) [3-29].

The clinical-pathological features of primary EESS have not been widely investigated yet. To the authors' knowledge, this is the first case reported of EESS arising in the upper left lobe of the lung in a 45-year-old woman without associated endometriosis and in the absence of a primary genital ESS. An extensive review of literature is also reported, along with differential diagnoses, immunohistochemical and molecular findings, pathogenetic hypotheses and treatment options.

\section{Case presentation}

\section{Clinical history}

In 2007, a 38-year-old female was hospitalized for an ulcerated uterine cervical lesion which, after cervical biopsies, showed an in situ squamous cell carcinoma. Subsequently, an abdominal CT scan revealed an enlarged, dishomogeneous uterus, with hypodense mass of $5 \mathrm{~cm}$ adjacent to the posterior wall of the bladder. Two months later, the patient underwent total abdominal hysterectomy with bilateral salpingectomy and pelvic lymphadenectomy. In the intraoperative phase, the uterus was found to be mobile and ovaries were normal. Neither enlarged lymph nodes nor peritoneal lesions or ascites were noted.

On histological examination of the surgical specimen, a well-differentiated squamous cell carcinoma in situ of the cervix, measuring $4 \mathrm{~mm}$ in maximum diameter, with basaloid morphology, was identified. Three additional leiomyomata of the uterine corpus, besides the larger one already identified on CT scan, were also microscopically found.

In 2014, the patient presented to medical observation with a pulmonary mass (Fig. 1). Upper left lobectomy was performed. The final pathologic diagnosis was carcinosarcoma of the lung.

A second histological revision of the lung surgical specimen was performed in March 2014 in the Pathology Unit of our Institute. The preferred diagnosis, after extensive immunohistochemical analyses, was spindle-cell sarcoma, consistent with high grade EESS.

Post-operative staging with thoracic, abdominal and pelvic CT scan did no have any abnormal findings and a follow-up was proposed. After five months, a CT scan was performed: it revealed a left pulmonary lesion with a maximum diameter of $18 \mathrm{~mm}$. Chemotherapy treatment with carboplatin AUC 5 and paclitaxel $175 \mathrm{mg} / \mathrm{mq}$ every three weeks was started. After three courses of antiblastic therapy, the lesion in the left lung appeared to be increased in volume (27 $\mathrm{mm}$ of diameter) on CT scan. After multidisciplinary discussion, a surgical intervention (atypical segmentectomy of lower lobe of the left lung) was performed.

Almost three months after surgical intervention, a new pulmonary lesion located in the right lung was detected by CT scan. The lesion was subsequently treated with radiofrequency ablation. As a consequence of the procedure, right pleural effusion after $24 \mathrm{~h}$ and after five days by the appearance of right pneumothorax after five days appeared. Shortly after tube insertion, additional radiographs were taken: they showeda rapid decrease in the size of the pneumothorax. The thoracic drainage was removed and patient was discharged from the hospital.

After one month, a CT scan was repeated. The scan showed surgical and radiofrequency ablation effects and a new pulmonary lesion of uncertain nature, measuring 4-5 mm of maximum diameter. Hormonal therapy with progestin (acetate medroxyprogesterone 1 gr daily) was prescribed.

No radiological signs of progression were noted until December 2015, when new lung lesions located in the lower lobe of the right lung and upper lobe of the left lung were detected on CT scan.

In January 2016, the patient referred the appearance of a soft tissue mass, rapidly enlarging, located in the left periscapular region. A tru-cut biopsy of the soft tissue lesion was performed: histological examination revealed a neoplastic lesion with spindle cell morphology, reminiscent of the upper left lobe EESS.

A second line polychemotherapy with epirubicin and ifosfamide was started. After three courses of chemotherapy, radiological evaluation through CT scan revealed a decrease of the diameter of the right lung lesion and the disappearance of the lesion in the left lung. At the follow-up visit, the patient was in good conditions well, with no clinical signs or symptoms of the disease and no pathological findings on CT scan; routine laboratory tests were normal.

Signed written consent was obtained from the patient for this case report.

\section{Methods}

Two and half-micron sections from formalin-fixed paraffin embedded tissue of the resected lobe and of the hysterectomy specimen were cut and immunohistochemical analysis was performed through an automated system (Benchmark-XT, Ventana, Tucson, AZ, US). The following primary antibodies were used:

CD117 (pathway c-kit, clone 9.7, pre-diluted; Ventana, Tucson, AZ, US), Estrogen receptor (monoclonal antibody, clone SP1, prediluted, Ventana), Progesteron receptor (monoclonal antibody, clone 1E2, prediluted, 


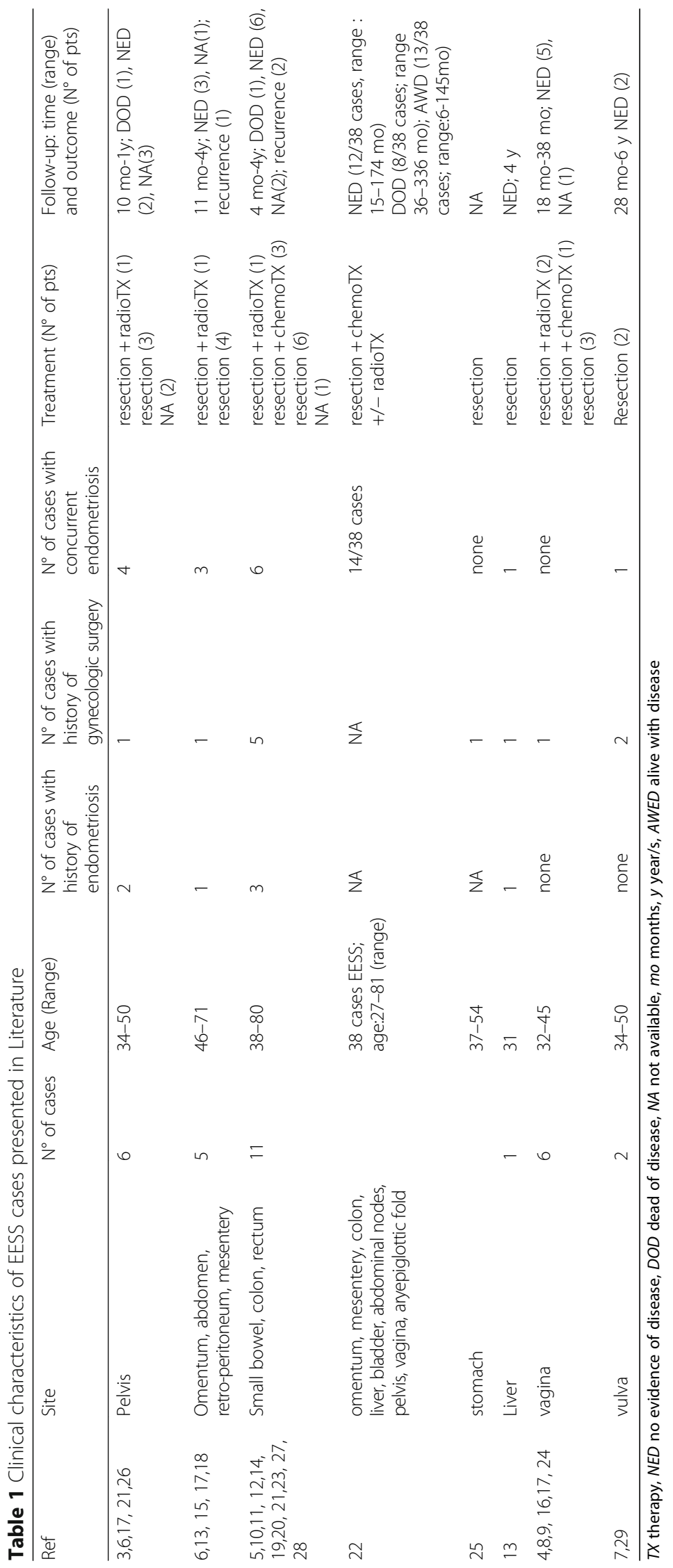




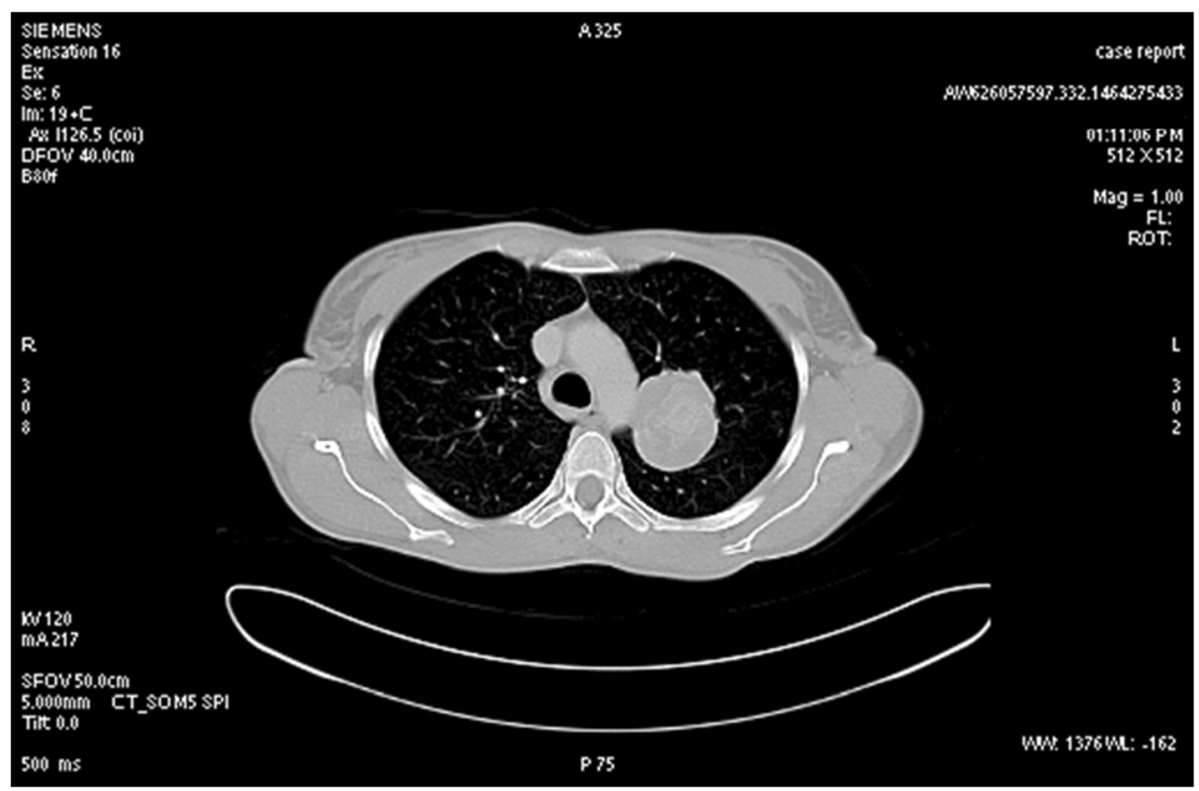

Fig. 1 Thoracic CT scan showing a mass (50 mm of maximum diameter) in the upper left lobe

Ventana), Ki67 (monoclonal antibody, clone 30.9, prediluted, Ventana), CD10 (monoclonal antibody, clone Sp67, prediluted, Ventana), CD34 (monoclonal antibody, clone QBEND/10; 1:400 dilution; Neomarkers, Freemont, CA, USA), CD31 (monoclonal antibody, clone JC70, Prediluted, Cell Marque, Rocklin, CA, US), Pankeratin (CkAE1/AE3/pCk26, pre-diluted, Ventana), MNF116 (monoclonal antibody, clone MNF116, prediluted, Diagnostic Biosystem, Pleasanton, CA, US), smooth muscle actin (SMA) (monoclonal antibody, clone 1A4, 1:100 dilution; DAKO, Glostrup, Denmark/ Carpinteria, CA, US), H-Caldesmon (monoclonal antibody, clone E89, prediluted, Ventana), S100 (polyclonal antibody, 1:400 dilution; DAKO), MDM2 (monoclonal antibody, clone IF2, 1:100 dilution, Calbiochem, Merk, Darmstardt, Germany), D2-40 (monoclonal antibody, clone podoplanin, prediluted, Cell Marque), CD99 (monoclonal antibody, clone o13, prediluted, Ventana), Myogenin (monoclonal antibody, clone FD5, 1:50 dilution, Cell Marque), Myoglobin (polyclonal, prediluted, Ventana), Vimentin (monoclonal antibody, clone V9, prediluted, Ventana), Desmin (monoclonal antibody, clone De-R-11, prediluted, Ventana), TTF1 (monoclonal antibody, clone 8G9G3/1, prediluted, Ventana).

The color was developed with 3.3'-diaminobenzidine (DAB), and the slides were counterstained with Meyer's hematoxylin. Appropriate positive and negative controls were run concurrently.

\section{Morphological findings}

The histological examination of hematoxylin and eosin stained slides of the pulmonary lesion showed uniform spindle cells organized in a diffuse pattern (Fig. 2a, b, c), with mild atypia and foci of necrosis (Fig. 2d), in a background of fibromyxoid stroma (Fig. 2d). The tumor cells had oval to round nuclei with inconspicuous nucleoli, and eosinophilic cytoplasms. Some small-sized thickwalled vessels were unevenly distributed among the stroma (Fig. 2a, d). Mitotic rate was high, ranging up to 20 mitoses per 10 high-power fields. Alveolar epithelium was focally entrapped by the neoplastic cells (Fig. 2a, c). Despite a thorough examination, endometriotic spots were not identified in the tumor or in adjacent nonneoplastic tissue.

A review of all slides from the hysterectomy specimen, which included the large lesion identified on CT scan plus three additional microscopically found leiomyomas, confirmed the original diagnosis of squamous carcinoma in situ of the cervix with leiomyomas of the uterine wall. No evidence of ESS or endometrial stromal nodules was found.

\section{Immunophenotipic findings}

On immunohistochemical staining, the tumor cells showed patchy and intense immunoreactivity for CD10 (Fig. 3a), estrogen receptor (Fig. 3e), and progesterone receptor (Fig. 3f), focal staining for CD99, and diffuse vimentin staining (Fig. 3b). Tumor cells also showed negative results for CD117, S-100 protein, and CD34, CD31, D2-40, MDM2, pan-keratin, H-caldesmon (positive in small vessels) (Fig. 3c), MNF116 (positive in the entrapped epithelial alveolar elements), TTF-1 (positive in the entrapped epithelial alveolar elements) (Fig. 3d), myogenin and myoglobin. Ki67 percentage of positive 


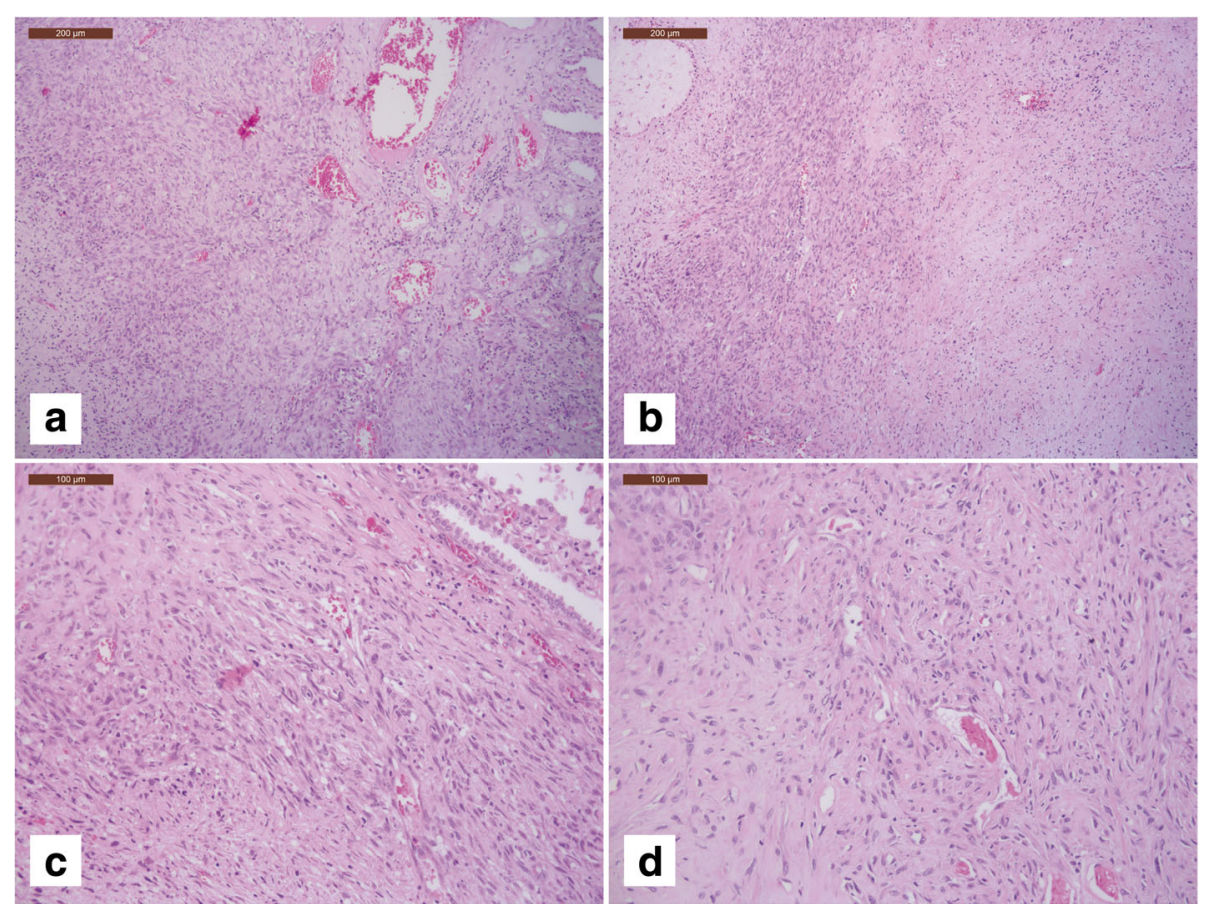

Fig. 2 a, b Panoramic view of the pulmonary lesion showing uniform spindle cells arranged in a fascicular pattern; alveolar epithelium is focally entrapped by the neoplastic cells (H\&E, 100X); c, d some small thinwalled blood vessels resembling spiral arterioles of late secretory endometrium were unevenly distributed among the stroma (H\&E, 100X); b, d, neoplastic cells show moderate atypia and foci of hyaline-type necrosis, in a background of fibromyxoid stroma); $\mathbf{d}$, the tumor cells had oval to plump spindle-shaped nuclei with finely granular chromatins, inconspicuous nucleoli, and amphophilic cytoplasms (H\&E, 200x)

nuclei ranged from 20 to $40 \%$. Limited smooth muscle differentiation was occasionally present and was focally positive for smooth muscle actin and desmin. The preferred diagnosis was EESS with high grade areas.

CD10 was completely negative (Fig. 4b) whereas estrogen and progesterone receptors (Fig. 4c, d, respectively) were positive, as expected, in leiomyomas from the previous hysterectomy specimen.

The periscapular soft tissue recurrence showed the same histological and immunohistochemical findings, except for the absence of staining for CD10, which displayed a patchy staining on the lung specimen; therefore, its absence on a tru-cut biopsy of periscapular soft tissues could be due to sampling from a non-staining area.

\section{Discussion}

Endometrial stromal sarcoma is a malignant tumor closely resembling stromal cells of proliferative-phase endometrial stromal cells. It is commonly associated with a delicate network of arterioles. Even when displaying classical histological features, an unusual site of occurrence may make the diagnosis challenging. Therefore, despite its rarity EESS should always be taken into consideration in the differential diagnosis for a woman with a thoracic or abdominal tumor with uniform cytologically bland cells resembling normal endometrial stroma.
On the other hand, in the gastrointestinal tract and extragenital sites, in the absence of endometriosis EESSs may be mistaken for other mesenchymal more common neoplasms [20], such as cellular leiomyoma and lowgrade leiomyosarcoma, solitary fibrous tumor and gastrointestinal stromal tumor (Table 2). In such cases, a large panel of immunohistochemical markers could be of help in establishing the diagnosis (Table 2). Regardless of the site of presentation, also peculiar histological features may be challenging for diagnosis, when noted in EESS [22]. When tubules-like structures are identified within spindle cell proliferations, also endometriosis and adenosarcoma are additional diagnoses that should be considered. On the other hand, EESS also can have glandular differentiation. In this case periglandular stromal condensation around benign glands and polypoid fronds composed of cellular stroma imparting a leaf-like appearance are morphological features more characteristic of adenosarcoma.

In the largest group of EESS described to date, one case arising in the larynx was initially diagnosed as monophasic synovial sarcoma [22] which is not usually included into the differential diagnoses of EESS as it frequently arises within the soft tissues of the limbs. Immunohistochemistry can once again be helpful (Table 2). Finally, the long time from primary genital ESS onset 


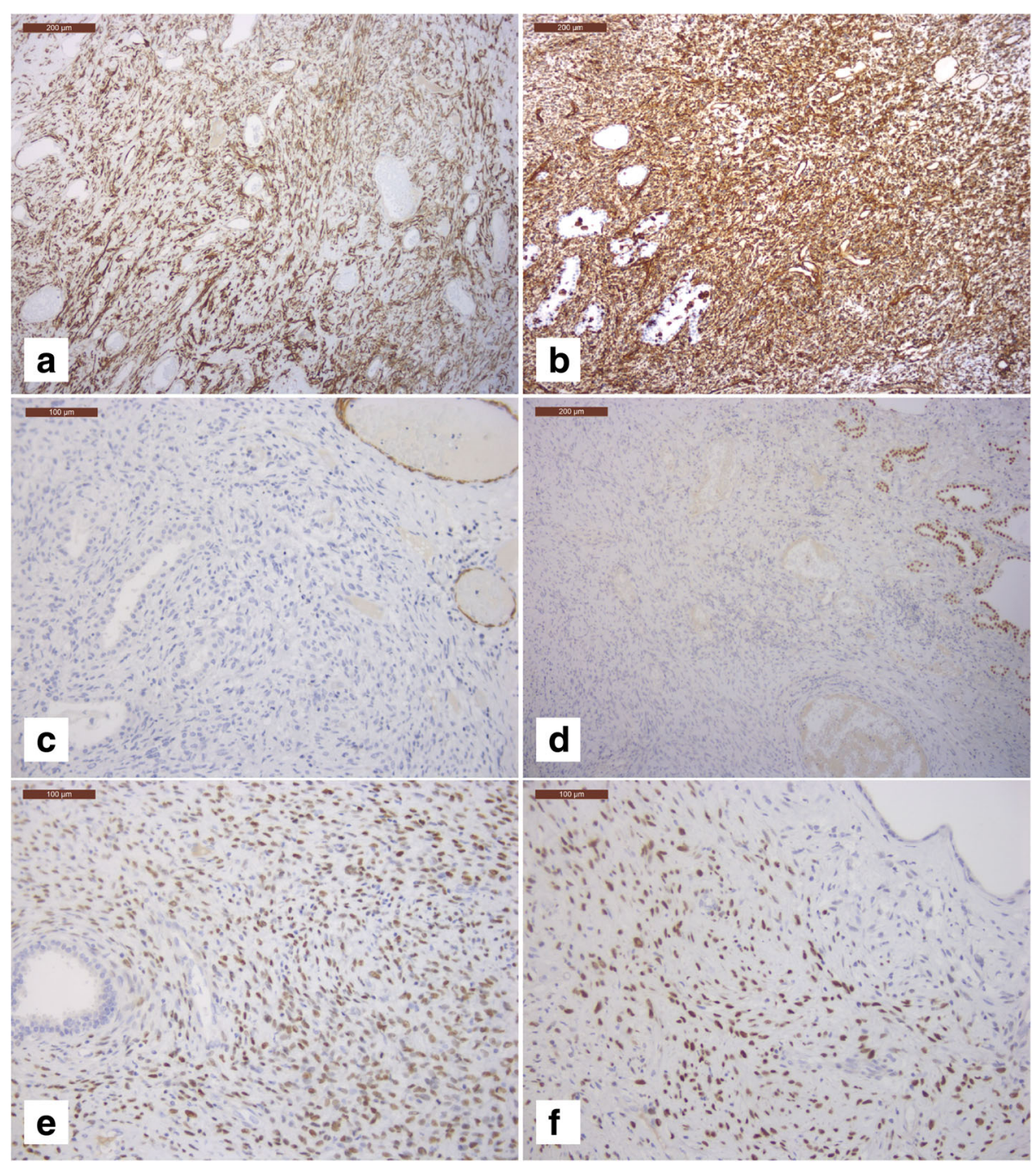

Fig. 3 Neoplastic cells showed patchy and intense immunoreactivity for CD10 (a, 100x), diffuse vimentin staining (b, 100x), negative staining for $\mathrm{H}$-Caldesmon (positive control staining in small vessels;upper left) (c, 100X), negative staining for TTF-1 (positive nuclear staining in the entrapped epithelial alveolar elements; right) (d, 100x), moderately diffuse nuclear staining for estrogen receptor (e, 200x), moderately diffuse nuclear staining for progesterone receptor $(\mathbf{f}, 200 x)$

and its recurrence and/or metastasis, requires a review of the clinical history of the patient and a second look at the slides from a previous hysterectomy specimen to rule out the possibility of an overlooked uterine ESS [2]. In our patient the hysterectomy specimen was extensively sampled and a review of all slides confirmed the original diagnosis.

Several hypotheses are invoked to explain the pathogenesis of EESS. Since in many cases (Table 1) endometriosis was found to be adjacent to EESS, it could be speculated that primary EESS arises from an ectopic focus of endometrial stroma. However, our case and few others, (listed in Table 1), indicate that the absence of associated endometriosis does not preclude primary EESS at that site. In these cases, either EESS may arise from an underlying endometriosis hidden by sarcomatous overgrowth [22] or it might derive de novo from the peritoneal/pleural (in our case) surface or the coelomic or subcoelomic multipotential epithelium [30, 31].

Recent molecular studies showed that ESS can be genetically heterogeneous. The most common alteration carried by ESS is the $\mathrm{t}(7 ; 17)$ (p15;q21) translocation, which results in JAZF1-SUZ12 gene fusion (also known as JJAZ1) [32]. However, such rearrangements rarely occur in ESS displaying different morphological features e.g., myxoid, epithelioid, fibrous, smooth muscle, and sex-cord histologic variants: thisreveal that other unknown molecular changes may be involved in the disease phenotypic presentation [32]. Other gene fusionsconcerning PHF1 and YWHAE genes, are much less frequent and are likely to be related with specific clinicopathological features [33]. Although molecular testing 


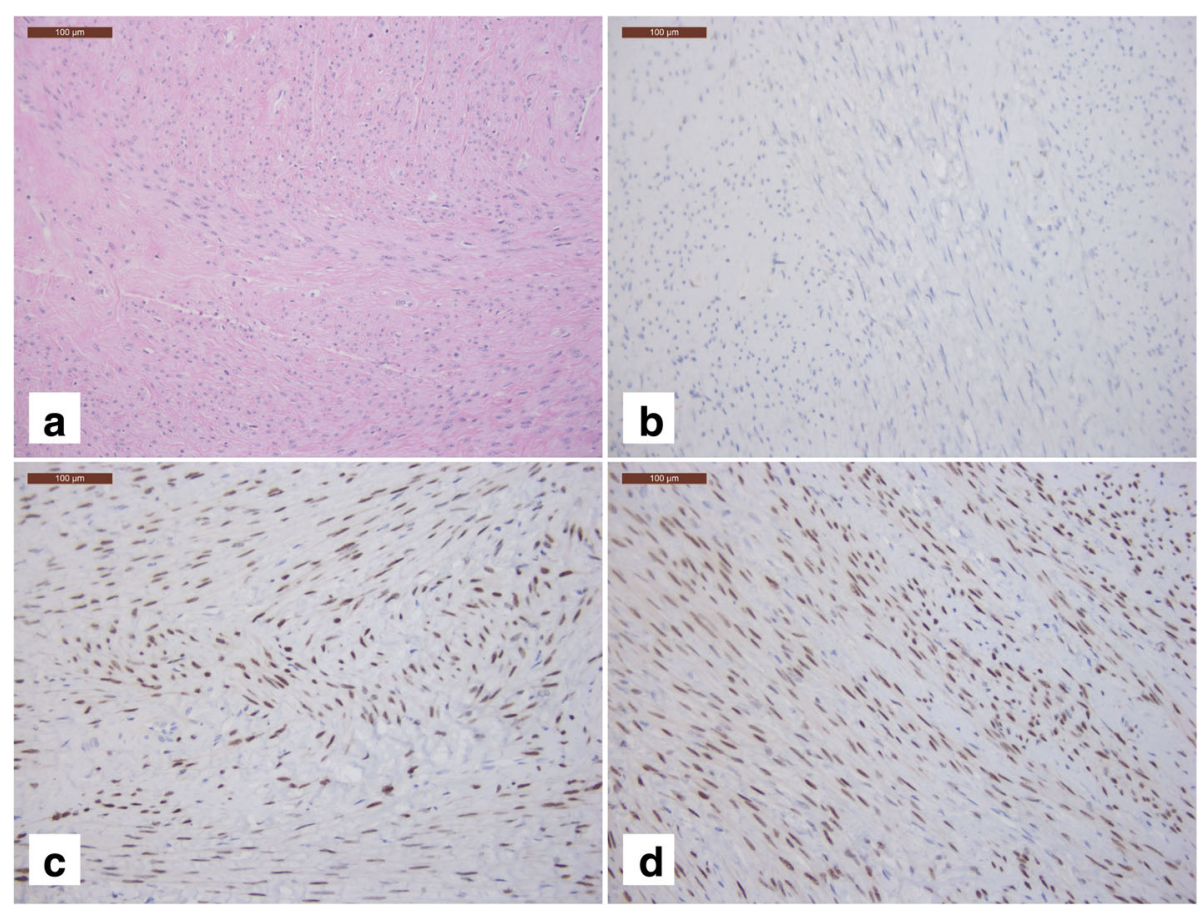

Fig. 4 Leiomyoma with classic morphology from previous hysterectomy specimen, showing intersecting fascicles of cigarshaped, spindle cells with eosinophilic cytoplasm (a, 200x); CD10 negative immunostaining (b, 200x); positive nuclear staining for estrogen receptor (c, 200x), positive nuclear staining for progesterone receptor $(\mathbf{d}, 200 \times)$

for the $\mathrm{t}(7 ; 17)(\mathrm{p} 15 ; \mathrm{q} 21)$ and associated gene fusion may be useful for confirming primary extrauterine endometrial stromal sarcoma, the low prevalence of the genetic aberration in this subset of patients limits the clinical utility of the analysis [21].

The behavior of EESS, compared to genital ESS, seems to be controversial. Although results are conflicting, it seems that the only feature associated with a worse prognosis is the presence of morphological features suggestive of dedifferentiation [22].
Given the rarity of these tumors, evidence-based data are not available to help guide treatment decisions. Surgery is generally regarded as the cornerstone of treatment for ESS. Complete cytoreductive surgery is recommended, especially in patients for whom this surgery could result in being residual-disease-free. Tumor-free margins are important in prognosis [34]. Extragenital ESS may have a high tendency for dissemination and metastasis in the omentum, mesentery, and abdominal or pelvic wall $[20,22]$. Despite this, most patients with

Table 2 Morphophenotypic features of the most common mesenchymal spindle cell neoplasms in the differential diagnosis of EESS

\begin{tabular}{|c|c|c|}
\hline Mesenchymal Neoplasm & Morphological features & Immunohistochemical markers \\
\hline $\begin{array}{l}\text { Cellular leiomyoma/low-grade } \\
\text { leiomyosarcoma }\end{array}$ & $\begin{array}{l}\text { characteristic intersecting fascicles of smooth muscle } \\
\text { cigarshaped spindle cells with eosinophilic cytoplasm } \\
\text { and perinuclear vacuolation, showing a smooth, pushing } \\
\text { margin and large, irregular, thick-walled blood vessels }\end{array}$ & $\begin{array}{l}\text { muscle-specific actin }+ \text {, smooth muscle actin }+ \text {, } \\
\text { desmin }+ \text {, ER }+ \text {, PgR+, CD10 }-/+, \mathrm{H} \text {-caldesmon }+\end{array}$ \\
\hline Gastrointestinal stromal tumor & $\begin{array}{l}\text { spindle cells with long tapering nuclei and abundant } \\
\text { clear or eosinophilic cytoplasm arranged in fascicles or } \\
\text { sheets; characteristically well circumscribed with pushing } \\
\text { borders }\end{array}$ & $\begin{array}{l}\text { CD34 +, DOG-1 +, CD117 +, CD10 -, ER -, PgR-; } \\
\text { muscle-specific actin -/+, smooth muscle actin } \\
-/+ \text {, desmin }-/+\end{array}$ \\
\hline Solitary fibrous tumor & $\begin{array}{l}\text { bland spindle cells haphazardly arranged in a dense } \\
\text { collagenous matrix but lacks the peculiar characteristic } \\
\text { vasculature of the ESS }\end{array}$ & CD34 +, CD10 -, ER -, PgR- \\
\hline Monophasic synovial sarcoma & most commonly involves the soft tissues of the extremities; & CD99 +, EMA +, CD10 -, ER -, PgR- \\
\hline ESS & $\begin{array}{l}\text { monomorphous plump spindle cells forming short regular } \\
\text { fascicles, evenly distributed arterioles and infiltrative border }\end{array}$ & $\begin{array}{l}\text { muscle-specific actin }-/+ \text {, smooth muscle actin }-/+ \text {, } \\
\text { desmin }-/+, E R+, \text { PgR }+, C D 10+, H \text {-caldesmon - }\end{array}$ \\
\hline
\end{tabular}


extrauterine ESS had prolonged disease-free intervals with late recurrences [20, 22]. The value of adjuvant therapy is controversial with no prospective studies showing a survival advantage associated with the use of chemotherapy or radiotherapy [34]. Nevertheless, adjuvant therapy is still considered in patients with metastatic or recurrent ESS. Radiotherapy may also have a palliative role [34].

\section{Conclusions}

In summary, we present in this study the first EESS of the lung reported to date. EESS is an uncommon tumor arising in women of any age, usually presents as a mass lesion in the abdomen or pelvic cavity. The knowledge of its potential extrauterine location and of peculiar morphophenotypic aspects are required for a correct diagnosis. Surgical resection is the most frequent treatment option, eventually followed by hormonal-therapy. EESS does not seem to have an aggressive behavior, and is likely to recur late after the initial treatment: therefore, a long-term clinical follow-up should be programmed.

\section{Abbreviations}

CT: Computed tomography; ESS: Endometrial stromal sarcoma; HGESS: High-grade endometrial stromal sarcoma; H\&E: Hematoxylin-eosin; LGESS: Low-grade endometrial stromal sarcoma; UESS: Undifferentiated endometrial stromal sarcoma

\section{Acknowledgments}

We thank Ms Laura Zannier and Ms Antonella Selva for their invaluable technical assistance and Ms Anna Vallerugo, MA, for the English editing

\section{Funding}

No funding was received for this case report.

\section{Availability of data and materials}

Please contact the Authors for data requests.

\section{Authors' contributions}

LA analyzed the data, reviewed the literature, took the pictures and wrote and revised the manuscript as a major contributor. VC performed the final diagnosis on the revision of slides, interpreted the immunohistochemical staining of slides, wrote and revised the manuscript and contributes for important intellectual content. SS, FS, GM and GB gave information about clinical history and follow up; MU contributed to the radiological findings and images. PT, GM helped to the final draft of the manuscript. GM, FS contributed to revision of the manuscript. Fl contributed to literature review. All authors have read and approved the final manuscript.

\section{Competing interests}

The authors declare that they have no competing interests.

\section{Consent for publication}

Informed consent was obtained from the patient for the publication of this case report and any accompanying images.

\section{Ethics approval and consent to participate}

Ethical approval for this study was obtained from the Scientific Committee Board of the Institute.

\section{Publisher's Note}

Springer Nature remains neutral with regard to jurisdictional claims in published maps and institutional affiliations.

\section{Author details}

${ }^{1}$ Pathology, IRCCS-National Cancer Institute, Via F. Gallini 2, 33081 Aviano, Italy. ${ }^{2}$ Gynecological Oncology Unit, IRCCS-National Cancer Institute, Aviano, Italy. ${ }^{3}$ Surgical Oncology, IRCCS-National Cancer Institute, Aviano, Italy. ${ }^{4}$ Department of Medical Oncology, IRCCS-National Cancer Institute, Aviano, Italy.

${ }^{5}$ Department of Radiology, IRCCS-National Cancer Institute, Aviano, Italy.

${ }^{6}$ Oncopath Lab, Floridia, Siracusa, Italy.

Received: 18 January 2017 Accepted: 17 April 2017

Published online: 02 May 2017

\section{References}

1. Kurman R, Carcangiu ML, Herrington C, et al. WHO classification of tumours of female reproductive organs. IARC WHO Classification of Tumours, No 6. Lyon: IARC press; 2014.

2. Oliva E, Clement PB, Young RH. Endometrial stromal tumors: an update on a group of tumors with a protean phenotype. Adv Anat Pathol. 2000;7(5): 257-81.

3. Ferraro LR, Hetz H, Carter H. Malignant endometriosis; pelvic endometriosis complicated by polypoid endometrioma of the colon and endometriotic sarcoma; report of a case and review of the literature. Obstet Gynecol. 1956;7(1):32-9.

4. Berkowitz RS, Ehrmann RL, Knapp RC. Endometrial stromal sarcoma arising from vaginal endometriosis. Obstet Gynecol. 1978:51(1 Suppl):34s-7.

5. Baiocchi G, Kavanagh JJ, Wharton JT. Endometrioid stromal sarcomas arising from ovarian and extraovarian endometriosis: report of two cases and review of the literature. Gynecol Oncol. 1990;36(1):147-51.

6. Fukunaga $\mathrm{M}$, Ishihara $\mathrm{A}$, Ushigome $\mathrm{S}$. Extrauterine low-grade endometrial stromal sarcoma: report of three cases. Pathol Int. 1998;48(4):297-302.

7. Irvin W, Pelkey T, Rice L, et al. Endometrial stromal sarcoma of the vulva arising in extraovarian endometriosis: a case report and literature review. Gynecol Oncol. 1998;71(2):313-6.

8. Kondi-Paphitis A, Smyrniotis B, Liapis A, et al. Stromal sarcoma arising on endometriosis. A clinicopathological and immunohistochemical study of 4 cases. Eur J Gynaecol Oncol. 1998;19(6):588-90.

9. Chang YC, Wang TY, Tzen CY. Endometrial stromal sarcoma of the vagina. Zhonghua Yi Xue Za Zhi (Taipei). 2000;63(9):714-9.

10. Yantiss RK, Clement PB, Young RH. Neoplastic and pre-neoplastic changes in gastrointestinal endometriosis: a study of 17 cases. Am J Surg Pathol. 2000;24(4):513-24.

11. Mourra N, Tiret E, Parc Y, et al. Endometrial stromal sarcoma of the rectosigmoid colon arising in extragonadal endometriosis and revealed by portal vein thrombosis. Arch Pathol Lab Med. 2001;125(8):1088-90.

12. Bosincu L, Massarelli G, Cossu RP, et al. Rectal endometrial stromal sarcoma arising in endometriosis: report of a case. Dis Colon Rectum. 2001;44(6):890-2.

13. Khan AW, Craig M, Jarmulowicz M, et al. Liver tumours due to endometriosis and endometrial stromal sarcoma. HPB (Oxford). 2002;4(1):43-5.

14. Cho HY, Kim MK, Cho SJ, et al. Endometrial stromal sarcoma of the sigmoid colon arising in endometriosis: a case report with a review of literatures. J Korean Med Sci. 2002;17(3):412-4.

15. Morrison C, Ramirez NC, Chan JK, et al. Endometrial stromal sarcoma of the retroperitoneum. Ann Diagn Pathol. 2002;6(5):312-8.

16. Corpa MV, Serafini EP, Bacchi CE. Low-grade endometrial stromal sarcoma presenting as vaginal nodule. Ann Diagn Pathol. 2004;8(5):295-8.

17. Kondi-Pafiti A, Spanidou-Carvouni H, Papadias K, et al. Malignant neoplasms arising in endometriosis: clinicopathological study of 14 cases. Clin Exp Obstet Gynecol. 2004;31(4):302-4.

18. Kovac D, Gasparovic I, Jasic M, et al. Endometrial stromal sarcoma arising in extrauterine endometriosis: a case report. Eur J Gynaecol Oncol. 2005; 26(1):113-6.

19. Rojas H, Wang J, Chase D, et al. Pathologic quiz case: a 46-year-old woman with 1-day history of abdominal pain and intestinal obstruction. Extrauterine low-grade endometrial stromal sarcoma. Arch Pathol Lab Med. 2005;129(2):e44-6.

20. Kim L, Choi SJ, Park IS, et al. Endometrial stromal sarcoma of the small bowel. Ann Diagn Pathol. 2008;12(2):128-33.

21. Amador-Ortiz C, Roma AA, Huettner PC, et al. JAZF1 and JJAZ1 gene fusion in primary extrauterine endometrial stromal sarcoma. Hum Pathol. 2011; 42(7):939-46.

22. Masand RP, Euscher ED, Deavers MT, et al. Endometrioid stromal sarcoma: a clinicopathologic study of 63 cases. Am J Surg Pathol. 2013;37(11):1635-47. 
23. Ayuso A, Fadare O, Khabele D. A case of extrauterine endometrial stromal sarcoma in the colon diagnosed three decades after hysterectomy for benign disease. Case Rep Obstet Gynecol. 2013;2013:202458.

24. Liu Z, Ding J, Li X, et al. Endometrial stromal sarcoma arising in vagina. Int J Clin Exp Pathol. 2013;6(12):2997-3002.

25. Jin M, Reynolds JP, Odronic Sl, et al. Primary gastric extra-uterine endometrial stromal sarcoma. Ann Diagn Pathol. 2014;18(3):187-90.

26. Ghosal T, Roy A, Kurian S. Primary extrauterine endometrial stromal sarcoma: Located in pelvic and abdominal tissue and arising in endometriosis. Indian J Pathol Microbiol. 2014;57(3):447-9.

27. Wang Q, Zhao X, Han P. Endometrial stromal sarcoma arising in colorectal endometriosis: a case report and review of the literature. Case Rep Obstet Gynecol. 2015;2015:534273.

28. Son $\mathrm{HJ}$, Kim JH, Kang DW, et al. Primary extrauterine endometrial stromal sarcoma in the sigmoid colon. Ann Coloproctol. 2015:31(2):68-73.

29. Zaza KJ, Arafah MA, Al-Badawi IA. Vulvar extrauterine endometrial stromal sarcoma: a case report and literature review. Hematol Oncol Stem Cell Ther. 2015;8(3):125-9.

30. Norris HJ, Taylor HB. Mesenchymal tumors of the uterus. I. A clinical and pathological study of 53 endometrial stromal tumors. Cancer. 1966;19(6): 755-66.

31. Lauchlan SC. The secondary mullerian system. Obstet Gynecol Surv. 1972; 27(3):133-46.

32. Chiang S, Oliva E. Recent developments in uterine mesenchymal neoplasms. Histopathology. 2013;62(1):124-37.

33. Lee $\mathrm{CH}$, Marino-Enriquez A, Ou W, et al. The clinicopathologic features of YWHAE-FAM22 endometrial stromal sarcomas: a histologically high-grade and clinically aggressive tumor. Am J Surg Pathol. 2012;36(5):641-53.

34. Rauh-Hain JA, del Carmen MG. Endometrial stromal sarcoma: a systematic review. Obstet Gynecol. 2013;122(3):676-83.

\section{Submit your next manuscript to BioMed Central and we will help you at every step:}

- We accept pre-submission inquiries

- Our selector tool helps you to find the most relevant journal

- We provide round the clock customer support

- Convenient online submission

- Thorough peer review

- Inclusion in PubMed and all major indexing services

- Maximum visibility for your research

Submit your manuscript at www.biomedcentral.com/submit

) Biomed Central 